\title{
Estimation of Permanent Magnet Synchronous Generator Performance with Artificial Neural Network Models
}

\author{
(D) Onursal ÇETIN ${ }^{1}$, (iDAdem DALCALI², (D Feyzullah TEMURTAŞ ${ }^{3}$ \\ ${ }^{1}$ Corresponding Author; Bandırma Onyedi Eylül Üniversitesi, Mühendislik ve Doğa Bilimleri Fakültesi, \\ Elektrik-Elektronik Mühendisliği Bölümü; ocetin@bandirma.edu.tr, 0000-0001-5220-3959 \\ ${ }^{2}$ Bandırma Onyedi Eylül Üniversitesi, Mühendislik ve Doğa Bilimleri Fakültesi, Elektrik-Elektronik \\ Mühendisliği Bölümü; adalcali@bandirma.edu.tr, 0000-0002-9940-0471 \\ ${ }^{3}$ Bandırma Onyedi Eylül Üniversitesi, Mühendislik ve Doğa Bilimleri Fakültesi, Elektrik-Elektronik \\ Mühendisliği; ftemurtas@bandirma.edu.tr, 0000-0002-3158-4032
}

Received 21 April 2020; Revised 25 April 2020; Accepted 27 April 2020; Published online 30 April 2020

\begin{abstract}
The interest in renewable energy sources has grown with the increase of environmental pollution and the decrease of fossil fuels. It is possible to provide energy supply security and diversity by using renewable energy sources. In this regard, wind energy, which is one of the renewable energy sources whose share in energy production increases day by day, emerges as a local and environmentally friendly solution. Many different types of generators are used in wind turbines and these have advantages and disadvantages according to each other. Permanent magnet synchronous generators (PMSG) are preferred because of their advantages such as high efficiency, high power density and being used directly in wind turbines without the need for gear system. In this study, the performance of the 2,5 kW PMSG, with a 14-pole surface placement, internal rotor, suitable for use in wind turbines, has been examined by changing the physical structure of the magnet. For this purpose, performance parameters such as total magnet consumption, efficiency, power loss have been successfully estimated using single and double hidden layered multi layer neural network (MLNN), elman neural network (ENN) and radial basis function neural network (RBFNN).
\end{abstract}

Keywords: multilayer neural network, elman neural network, radial basis function neural network, permanent magnet synchronous generator

\section{Sabit Mıknatıslı Senkron Generatör Performansının Yapay Sinir Ağı Modelleri ile Kestirimi}

\section{Öz}

Çevre kirliliğinin artması ve fosil yakıtların azalması ile yenilenebilir enerji kaynaklarına ilgi artmıştır. Yenilenebilir enerji kaynaklarını kullanarak enerji arz güvenliğini ve çeşitliliğini sağlamak mümkündür. Bu bağlamda, enerji üretiminde payı her geçen gün artan yenilenebilir enerji kaynaklarından biri olan rüzgâr enerjisi, yerel ve çevre dostu bir çözüm olarak ortaya çıkmaktadır. Rüzgâr türbinlerinde birçok farklı tipte jeneratör kullanılmaktadır ve bunlar birbirlerine göre avantaj ve dezavantajlara sahiptir. Sabit mıknatıslı senkron generatörler (SMSG) yüksek verim, yüksek güç yoğunluğu ve dişli sistemine gerek olmadan direkt olarak rüzgâr türbinlerinde kullanılma gibi avantajlarından dolayı tercih edilmektedirler. Bu çalışmada, rüzgâr türbinlerinde kullanıma uygun 14-kutuplu yüzey yerleştirmeli, içten rotorlu, 2,5 kW SMSG’nin performansı mıknatısın fiziksel yapısı değiştirilerek incelenmiştir. Bu amaçla toplam kullanılan mıknatıs miktarı, verim, güç kaybı gibi performans parametreleri tek ve iki gizli katmana sahip çok katmanlı sinir ağı (MLNN), elman sinir ağı (ENN) ve radyal tabanlı fonksiyon sinir ağı (RBFNN) kullanılarak başarılı bir şekilde kestirilmiştir.

Anahtar Kelimeler: çok katmanlı sinir ağı, elman sinir ağı, radyal tabanlı fonksiyon sinir ağı, sabit mıknatıslı senkron generator 
Çetin et. al

\section{Giriş}

Gelişen teknoloji ve artan nüfus, elektrik enerjisine olan ihtiyacı her geçen gün arttırmaktadır. Azalan fosil yakıt kaynaklarıyla birlikte artan çevresel endişeler enerjinin arz güvenliği sorununu ön plana çıkarmıştır. Yenilenebilir enerji kaynakları ucuz, yerel ve çevre dostu bir enerji türü olması sebebiyle bu soruna çözüm olarak ön plana çıkmaktadırlar. Yenilenebilir enerji kaynaklarından faydalanılarak enerji arz güvenliğinin sağlanması ve çeşitliliğinin arttırılması için çalışmalar yoğun bir şeklide devam etmektedir. Yenilenebilir kaynaklar enerji güvenirliliğinin arttırılması, dışa bağımlılığın azaltılması ve çevre problemleri çözümlerinde önemli rol oynamaktadır [1,2]. Bununla birlikte, yerel çözüm olan bu kaynakların kullanımı ile cari açığın önemli bir bileşeni olan enerji ithalatının da azalması sağlanabilir [2]. Hidrolik, rüzgâr, güneş, jeotermal ve biyokütle başlıca yenilenebilir enerji kaynakları olarak sınıflandırılabilir. Son yıllarda rüzgâr enerjisi ile elektrik üretiminde önemli bir artış görülmektedir. Türkiye'nin rüzgâr enerjisi kurulu gücü 2010 y1lında 1320,2 MW iken 2018 y1lında 7005,4 MW seviyesine çıkmıştır [3]. 2019 yılında Türkiye'de üretilen toplam elektrik enerjisi 289815,303 GWh iken rüzgâr kaynaklı toplam üretim 21512,28 GWh olarak gerçekleşmiştir. Buna göre rüzgârın elektrik üretimindeki payı bir önceki yıla göre yaklaşık \%9,4 artış göstererek \% 7,42 olmuştur [4].

Rüzgâr türbinlerinde birçok generatör çeşidi kullanılmaktadır. Kullanılan generatörlerin birbirine göre birçok avantaj ve dezavantajları mevcuttur [5]. Kullanılan generatörler arasında sabit mıknatıslı senkron generatörler (SMSG) yüksek güç yoğunluğu ve verim avantajları ile ön plana çıkmaktadırlar. NdFeB alaşımlı kalıcı mıknatısların keşfedilmesi ve motor sürücü teknolojilerinde meydana gelen gelişmeler ile sabit mıknatıslı makinalar hızlı bir şekilde gelişim göstermişlerdir. NdFeB tipi mıknatıslar yüksek BHmax çarpımına sahip olduklarından elektrik makinalarında yaygın olarak kullanılmaktadır. Bu tip mıknatısların kullanımı ile yüksek hava aralığı akı yoğunluğuna sahip kompakt makinalar elde edilebilmektedir. Kalıcı mıknatıslı makinalar düşük devir ve değişken hız uygulamalarında endüstride sıklıkla tercih edilmektedirler. Verim ve güç katsayısı gibi parametrelerin, dönüş hızından bağımsız olmasından dolayı bu makinalar düşük devir uygulamaları için oldukça uygundur [6-8].

Elektrik makinalarının tasarımı gerçekleştirilirken elektromanyetik, ısıl ve mekanik kıstaslar dikkate alınmalıdır. Elektrik makinalarının performansı, geometrik yapısı ve kullanılan malzemelerin karakteristiklerine bağlıdır. Makinanın geometrik yapısındaki değişlikler doğrudan eşdeğer manyetik ve elektrik devre modelini etkileyeceğinden makinanın performansını da değiştirir. Gerçekleştirilen tasarımın, maliyet ve istenilen performans açısından endüstriyel bir ürün olabilmesi için birçok ileri çalışmaya ihtiyaç duyulmaktadır $[9,10]$. Elektrik makinalarının tasarımında sonlu eleman ve sonlu fark gibi yaklaşım metotları kullanılarak makinanın istenilen tasarımının ve davranış modelinin oluşturulması mümkündür. Elektrik makinalarının, sonlu elemanlar metodu (SEM) kullanılarak yüksek doğrulukta elektromanyetik parametreleri belirlenebilir. Elektrik makinasının 2 boyutlu (2B) ve 3 boyutlu (3B) modeli oluşturularak sonlu elemanlar analizleri (SEA) yapılabilmektedir. Bu analizlerin gerçekleştirilmesiyle sargı endüktansları, indüklenen gerilim, nüve kayıpları, manyetik akı yoğunlukları gibi çıkış parametreleri elde edilebilir. Ancak, gerçekleştirilen tasarım ve analiz işlemleri zaman alıcı çalışmalardan oluşmaktadır $[11,12]$.

SEM, sürekli olduğu bölge üzerinde kısmi diferansiyel denklemler yardımıyla belirlenen değişkenlerin yaklaşık sayısal çözümlerini bulmak amacıyla kullanılan bir yöntemdir. Bu yöntemde çözümü gerçekleştirilecek kısım, sonlu sayıda küçük ağ yapılarına (bölge) ayrılarak çözümü istenen değişkenin bu bölgelerde sürekli olduğu ve diferansiyel denklemin her eleman üzerinde geçerli olduğu varsayılır. Bölgedeki bir noktada çözümü elde etmek için, noktayı çevreleyen elemanların belirlenen noktaya katkıları dikkate alınır. Bu yüzden, bölgedeki düğümlere ilişkin büyüklükler zincirleme şekilde birbirine bağlanmış olur. Sonuç olarak, düğüm sayısı kadar diferansiyel denklemi olan doğrusal denklem takımı çıkartılır. Denklem takımının çözümü ile istenen parametreler hesaplanabilir $[11,13]$. Ancak bu metodun kullanımı için çok fazla hesaplama ve zaman gereklidir. Ayrıca bu hesaplama süresi ve karmaşıklığı, oluşturulacak model ve istenilen doğruluk ile de artış gösterebilecektir. Bu durum, tasarımcıyı doğruluk ve hesaplama yükü arasında bir karar vermek zorunda birakabilmektedir.

Esnek hesaplama yöntemleri, son yıllarda elektrik makinalarının tasarımında ve özellikle kontrolünde başarılı bir şekilde kullanılmaktadır. Bu yöntemler, geleneksel matematiksel metotlarla çözülemeyen 
problemlere çözüm üretmek amacıyla bir dizi hesaplama yaklaşımı kullanmaktadırlar. Esnek hesaplama yöntemleri kullanılarak SEA parametrelerinin iyileştirilmesi yoluyla döner elektrik makinalarının verimlerinin önemli ölçüde arttırıldığ görülmektedir [14]. Bu açıdan değerlendirildiğinde yüksek performanslı elektrik makinalarının geliştirilmesi, esnek hesaplama tekniklerinin kullanılması ve geliştirilmesi ile doğrudan ilişkilidir. Literatürde esnek hesaplama yöntemlerinin kullanımı ile elektrik makinalarının kontrölünde birçok çalışma olmasına rağmen özellikle elektrik makinalarının tasarımı konularında yapılan çalışmalar kısıtlıdır [14]. Elektrik makinaları uygulama örnekleri incelendiğinde, Dalcalı ve diğerleri çalışmalarında tek ve iki gizli katmandan oluşan çok katmanlı sinir ağı modeli kullanarak sarg1 içerisinde hareket eden cisim üzerindeki kuvvet kestirimini başarı ile gerçekleştirmişlerdir [15]. Çelik ve diğerleri eksenel akılı sabit mıknatıslı senkron generatörün verimliliğini ve çıkış gücünü tahmin etmek için ileri beslemeli çok katmanlı bir yapay sinir ağı modeli önermişlerdir. Gerçekleştirilen testler önerilen ağ yapısının oldukça uygun olduğunu göstermiştir. Böylelikle sabit mıknatıslı bir generatörde verim ve güç ifadelerinin sinir ağı yapıları kullanılarak tahmin edilebileceğini çalışmalarında sunmuşlardır [16]. Genel olarak, yapay sinir ağı teknikleri kullanılarak geliştirilen makalelerin sonuçlarına göre, bu yöntemin başarı ile uygulanabileceği söylenebilir.

Bu çalışmada, rüzgâr türbinlerinde kullanılabilen 14-kutuplu 2,5 kW anma gücünde yüzey yerleştirmeli, içten rotorlu, sabit mıknatıslı senkron generatörün tasarımı gerçekleştirilmiştir. Mıknatıs geometrisi ve dolayısı ile toplam mıknatıs kullanımı motor performansı üzerinde önemli bir yere sahiptir. Çalışmada rotor mıknatıslarının kaykı (skew) miktarı, kutup yayı/ kutup adımı oranı, kutup yay ofseti ve mıknatıs kalınlığının, generatörün verim, çıkış gücü, toplam güç kaybı, vuruntu torku, toplam harmonik bozulması (total harmonic distortion-THD) ve toplam mıknatıs ağırlığına etkisi radyal tabanlı fonksiyon sinir ağı, çok katmanlı sinir ağı ve elman sinir ağ 1 modelleri kullanılarak yüksek doğrulukla tahmin edilmiştir.

\section{Sabit Mıknatıslı Senkron Generatör Modeli}

Elektrik makinalarının tasarımında en az malzeme kullanımı ile en küçük hacimden en fazla güç elde edilmek istenmektedir. Sabit mıknatıslı makinalar, asenkron ve anahtarlamalı tip relüktans makinalara kıyasla yüksek birim güç ve tork yoğunluğuna sahiptirler [17,18]. SMSG’ler kolay üretim, düşük tork dalgalanması, yüksek verim ve yüksek güç yoğunluğu özelliklerine sahiptirler. Sabit mıknatıslı generatörler dişli sistemine gerek duymaksızın direkt olarak rüzgâr türbinlerinde kullanılabilirler. $\mathrm{Bu}$ durum SMSG'lerin rüzgâr türbinlerinde yoğunlukla kullanılmasını sağlamaktadır [19]. Çalışmada kullanılan generatörün tasarım parametreleri Tablo 1'de verilmektedir.

Tablo 1 PMSG'ün tasarım parametreleri

\begin{tabular}{|c|c|c|c|}
\hline Parametre & Değer & Parametre & Değer \\
\hline Anma gücü (W) & 2500 & Kutup sayısı & 14 \\
\hline Anma hızı (d/d) & 428,5 & Oluk sayısı & 84 \\
\hline Anma gerilimi (V) & 120 & Nüve malzemesi & M470-50A \\
\hline Stator Dış Çapı (mm) & 280 & Miknatıs malzemesi & N35 \\
\hline Rotor Dış Çapı $(\mathrm{mm})$ & 198,4 & Oluk başına iletken & 33 \\
\hline Paket Uzunluğu $(\mathrm{mm})$ & 54 & Hava aralığı $(\mathrm{mm})$ & 1,8 \\
\hline
\end{tabular}

Generatörün tasarım detayları ve matematiksel modeli, içeriğin uzunluğu ve tek başına farklı bir çalışmanın konusunu oluşturması nedeniyle burada sunulmamıştır. Matematiksel modeli ve tasarım detayları ilgili çalışmalardan $[7,8,20]$ bulunabilir. Şekil 1'de ilk tasarıma ait generatörün 3B modeli ve kesit görünümü verilmiştir. 

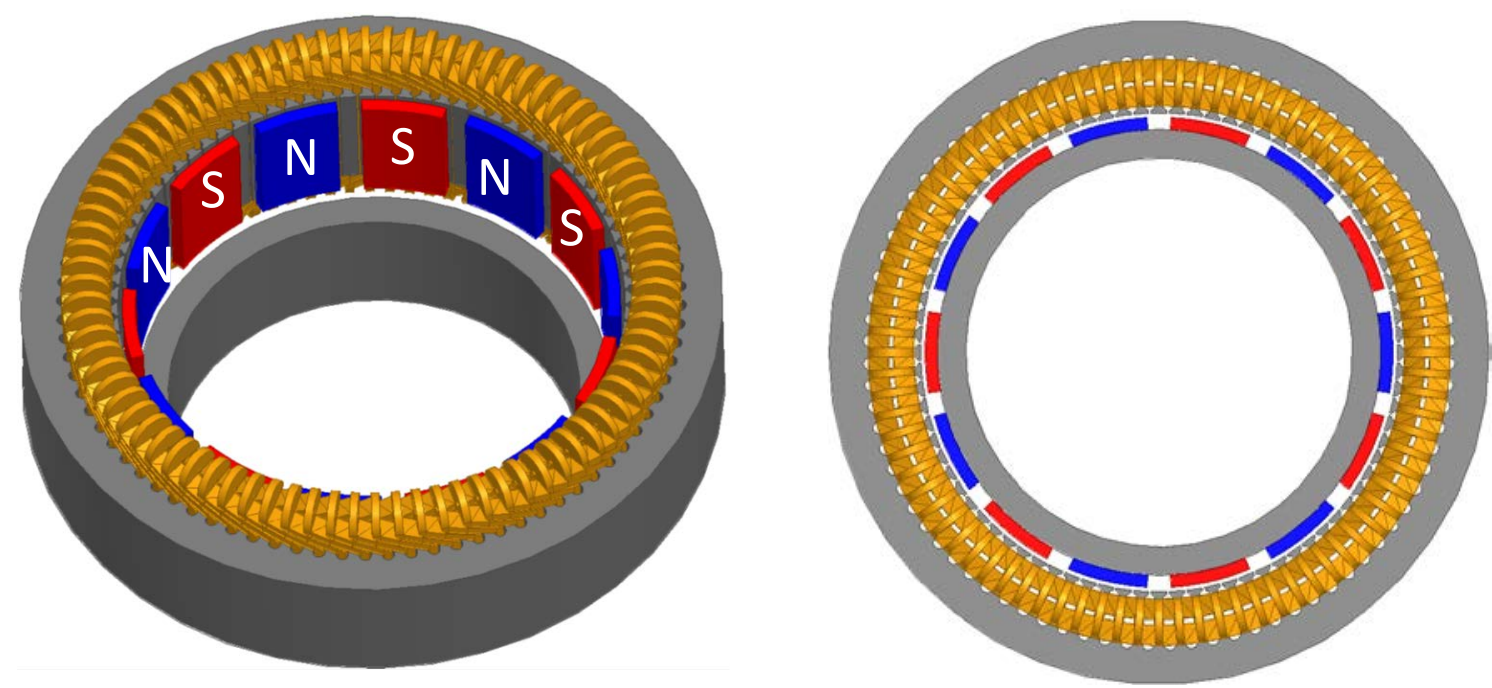

Şekil 1 Tasarlanan generatörün 3B modeli ve kesit görünümü

İlk tasarımı yapılan generatörün anma yükündeki performansı Tablo 2'de sunulmuştur.

Tablo 2 Analiz sonuçları

\begin{tabular}{|c|c|}
\hline Parametre & Değer \\
\hline Çıkış gücü (W) & 2520 \\
\hline Verim (\%) & 88,33 \\
\hline Toplam güç kayıpları (W) & 332,98 \\
\hline Toplam mıknatıs ağırlığı (kg) & 0,95 \\
\hline Stator diş akı yoğunluğu (T) & 1,70 \\
\hline Hava aralığı akı yoğunluğu (T) & 0,79 \\
\hline Vuruntu torku (Nm) & 0,49 \\
\hline Stator oluk doluluk oranı (\%) & 68,4 \\
\hline Stator sargı faktörü & 0,94 \\
\hline
\end{tabular}

Generatör performansı üzerinde mıknatıs geometrisinin önemi büyüktür. Sabit mıknatıslı yapıda mıknatıslar rotora gömülü veya yüzey yerleştirmeli olarak üretilebilmektedir. Yüzey yerleştirmeli yapı, yüksek kutup sayısında daha küçük rotor çapına imkân sağlamaktadır [21]. Çalışmada yüzey yerleştirmeli yapı tercih edildiğinden, mıknatıs geometrisinin değişkenleri bu kriter ve geometrik kıstaslar göz önünde bulundurularak belirlenmiştir. Çalışmada dört kriter göz önüne alınmıştır. İlki kutup yayı/kutup adımı oranı olup kutuplar arasındaki açıklığı ifade etmektedir. İkincisi mıknatıs kalınlığıdır. Diğer bir değişken ise mıknatısın kenarlarından basıklık düzeyini ifade eden kutup yay ofset miktarıdır. Son kriter ise mıknatısın çarpıklığını ifade eden skew miktarıdır. Tablo 3 'te belirlenen kriterlerin çalışmada alınan alt ve üst limitleri verilmiştir.

Tablo 3 Parametrelerin limitleri

\begin{tabular}{|c|c|}
\hline Parametre & Belirlenen aralık \\
\hline Kutup yayı/Kutup adımı oranı & $0,7 \leq \mathrm{X} 1 \leq 0,9$ \\
\hline Miknatıs kalınlığı (mm) & $4,7 \leq \mathrm{X} 2 \leq 5,5$ \\
\hline Kutup yay ofseti (mm) & $0 \leq \mathrm{X} 3 \leq 50$ \\
\hline Kaykı (Skew) & $0 \leq \mathrm{X} 4 \leq 1$ \\
\hline
\end{tabular}

$\mathrm{Bu}$ parametreler yapay sinir ağ modellerinin giriş değişkeni olarak belirlenmiştir. Optimum generatör tasarımı için sabit mıknatıslı bir generatörde dikkate alınması gereken en önemli faktörler verimlilik, 
vuruntu torku, maliyet ve toplam harmonik bozulma miktarı olarak görülebilir. Bu anlamda generatörün verimi, çıkış gücü, toplam güç kaybı, vuruntu torku, toplam harmonik bozulma miktarı ve toplam mıknatıs ağırlığı çıkış olarak belirlenmiştir.

\section{Yapay Sinir Ăğı Modelleri}

Başarılı bir sinir ağı modeli geliştirmek için ağ mimarisinin oluşturulması, öğrenme algoritmasının belirlenmesi, aktivasyon fonksiyonunun seçilmesi, eğitim ve test verilerinin üretilmesi önemlidir [15]. $\mathrm{Bu}$ çalışmada üç farklı sinir ağı modeli kullanılmıştır.

\subsection{Elman Sinir Ăğ}

$\mathrm{Bu}$ çalışmanın ilk aşamasında performans tahmini için ENN kullanılmıştır [22]. İleri beslemeli sinir ağlarında, giriş sinyalleri giriş katmanından çıkış katmanına doğru akarken ENN modelinde verinin geri yönde akışını sağlayan geri besleme döngüleri de mevcuttur. Bu durumda, ağın çıkışı hem mevcut hem de önceki girişin durumuna göre belirlenmektedir. Geri bildirim bağlantılarının uygun değerlerde seçilmesi Elman sinir ağının başarısını doğrudan etkilemektedir [23]. Şekil 2'de gösterilen ağ yapısı çok katmanlı olup giriş katmanı, tekrarlayan gizli katman ve çıkış katmanından oluşmaktadır.

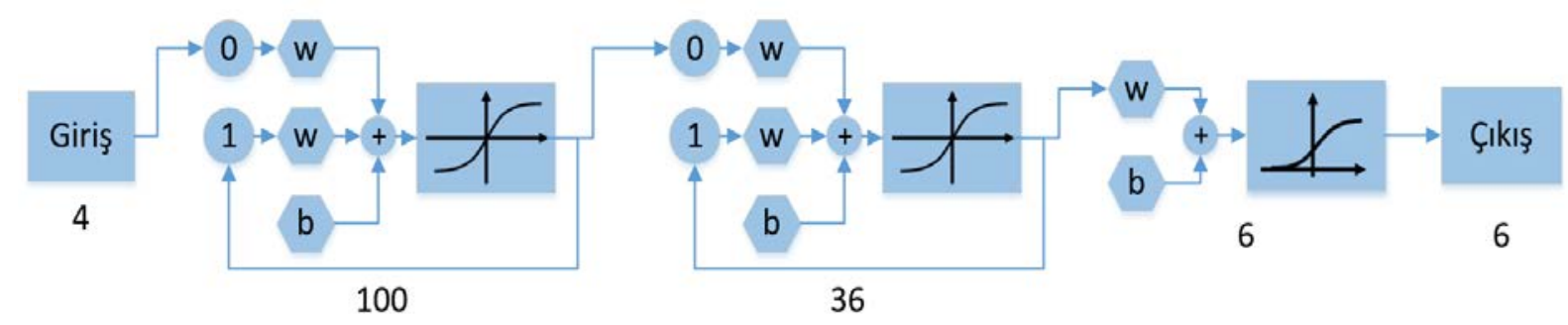

Şekil 2 Elman sinir ağı yapısı

İki gizli katmana sahip ENN modeli giriş katmanından çıkış katmanına sırasıyla 4, 100, 36 ve 6 nörona sahiptir. Gizli katmanlarda aktivasyon fonksiyonu olarak hiperbolik tanjant fonksiyonu kullanılmıştır. Çıkış katmanında ise logaritmik sigmoid fonksiyonu kullanılmıştır. ENN modelinde kullanılan eşitlikler Denklem 1-3'te verilmiştir [22].

$$
\begin{gathered}
X_{j}^{h 1}(n)=\frac{2}{1+\exp \left(-2\left(b_{j}^{h 1}(n)+\sum_{i=1}^{N} w_{i j}^{h 1}(n) \cdot U_{i}(n)+\sum_{i=N+1}^{N+N_{1}} w_{i j}^{h 1}(n) \cdot X_{i}^{h 1}(n-1)\right)\right)}-1 \\
X_{k}^{h 2}(n)=\frac{2}{1+\exp \left(-2\left(b_{k}^{h 2}(n)+\sum_{j=1}^{N_{1}} w_{j k}^{h 2}(n) \cdot X_{j}^{h_{1}}(n)+\sum_{j=N_{1}+1}^{N_{1}+N_{2}} w_{j k}^{h 2}(n) \cdot X_{j}^{h 2}(n-1)\right)\right)}-1 \\
Y_{\ell}(n)=\frac{1}{1+\exp \left(b_{\ell}^{o}(n)+\sum_{k=1}^{N_{3}} w_{k \ell}^{h o}(n) \cdot X_{k}^{2}(n)\right)}
\end{gathered}
$$

burada $j$ değeri [ $1-N_{1}$ ]aralığındadır ve $N_{1}$ ilk gizli katmanın düğüm sayısını, $k$ değeri $\left[1-N_{2}\right]$ aralığındadır ve $N_{2}$ ikinci gizli katmanın dügüm sayısını, $\ell$ değeri $\left[1-N_{3}\right]$ aralığındadır ve $N_{3}$ çıkış katmanının düğüm sayısını, $w_{i j}^{h 1}$ ilk gizli katmanın ağırlıklarını, $w_{j k}^{h 2}$ ikinci gizli katmanın ağırlıklarını, $w_{k \ell}^{h o}$ çıkış katmanının ağılıklarını, $b_{j}^{h 1}$ ilk gizli katmanın bias değerlerini, $b_{k}^{h 2}$ ikinci gizli katmanın bias değerlerini, $b_{\ell}^{o}$ çıkış katmanının bias değerlerini, $U_{i}(n)$ ağın girişlerini, $X_{i}^{h 1}(n-1)$ ilk gizli katmanın zaman gecikmeli çıktılarını ve $X_{i}^{h 2}(n-1)$ ikinci gizli katmanın zaman gecikmeli çıtılarını ifade etmektedir. 
ENN modelinin eğitimi için ölçeklendirilmiş eşleştirmeli gradyan geri yayılım algoritması (Scaled Conjugate Gradient-SCG) kullanılmıştır. Moller [24] tarafından geliştirilen yöntem adım büyüklüğünü hesaplarken ikinci dereceden türevleri kullanır. SCG algoritmasının detaylı hesaplamalarına [24] çalışmasından ulaşılabilir.

\section{2 Çok Katmanlı Sinir A $\breve{g} ı$}

Yapay sinir ağı modelleri arasında en çok kullanılan yöntemlerden biri bilginin giriş katmanından çıkış katmanına doğru aktığı MLNN yapısıdır [23]. Çalışmanın ikinci aşamasında SMSG'lerin performansını tahmin etmek amacıyla tek ve iki gizli katmandan oluşan MLNN modelleri kullanılmıştır. Giriş katmanından çıkış katmanına 4, 100 ve 6 nörondan oluşan tek gizli katmanlı ve 4, 26, 44 ve 6 nörondan oluşan iki gizli katmanlı MLNN ağ yapıları sırasıyla Şekil 3 ve Şekil 4’te gösterilmiştir.

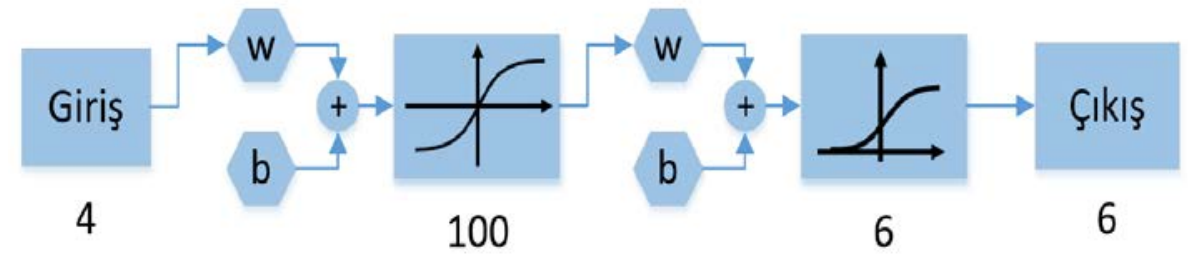

Şekil 3 Çok katmanlı ăg yapısı (Tek gizli katman)

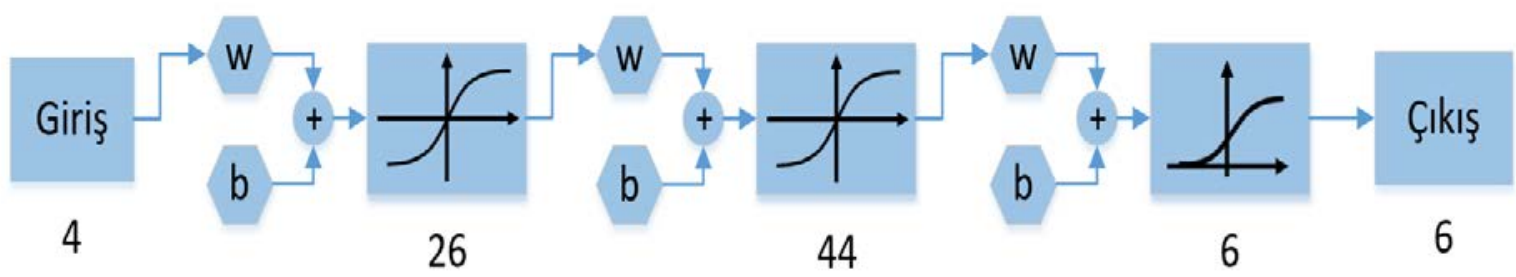

Şekil 4 Çok katmanlı ağ yapısı (İki gizli katman)

Her iki ağ için de gizli katmanlarda aktivasyon fonksiyonu olarak hiperbolik tanjant fonksiyonu, çıkış katmanlarında ise logaritmik sigmoid fonksiyonu kullanılmıştır. MLNN modelinde kullanılan eşitlikler Denklem 4-6'da verilmiştir [22].

$$
\begin{aligned}
X^{i h}(n) & =\frac{2}{1+\exp \left(-2\left(w^{i h}(n) \times u(n)+b^{i h}(n)\right)\right)}-1 \\
X^{h h}(n) & =\frac{2}{1+\exp \left(-2\left(w^{h h}(n) \times X^{i h}(n)+b^{h h}(n)\right)\right)}-1 \\
Y(n) & =\frac{1}{1+\exp \left(-1\left(w^{h o}(n) \times X^{h h}(n)+b^{h o}(n)\right)\right)}
\end{aligned}
$$

burada $\boldsymbol{u}(\boldsymbol{n})$ ağın giriş değerlerini, $\boldsymbol{X}^{\text {ih }}$ ilk gizli katmanın çıktılarını, $\boldsymbol{X}^{\boldsymbol{h} \boldsymbol{h}}$ ikinci gizli katmanın çıktılarını, $\boldsymbol{w}^{\boldsymbol{i} \boldsymbol{h}}$ ilk gizli katmanın ağırlık değerlerini, $\boldsymbol{w}^{\boldsymbol{h} \boldsymbol{h}}$ ikinci gizli katmanın ağılık değerlerini, $\boldsymbol{w}^{\boldsymbol{h} \boldsymbol{}}$ çıkış katmanının ağırlık değerlerini, $\boldsymbol{b}^{\boldsymbol{i h}}$ ilk gizli katmanın bias değerlerini, $\boldsymbol{b}^{\boldsymbol{h} \boldsymbol{h}}$ ikinci gizli katmanın bias değerlerini, $\boldsymbol{b}^{\boldsymbol{h o}}$ çıkış katmanının bias değerlerini, $\boldsymbol{Y}(\boldsymbol{n})$ ağın çıkış değerlerini ifade etmektedir.

Çok katmanlı sinir ağının eğitimi için kullanılan Levenberg - Marquardt (LM) algoritması GaussNewton ile gradyan iniş yöntemi arasında enterpolasyon yapar [25]. LM algoritması bu iki yöntemin sınırlamalarını kaldırır. LM algoritmasının detaylı hesaplamaları [25, 26]'da mevcuttur.

\subsection{Radyal Tabanlı Fonksiyon Sinir Ăgı}

Çalışmanın son aşamasında, SMSG'lerin performansını tahmin etmek amacıyla radyal tabanlı fonksiyon sinir ağı kullanılmıştır. Şekil 5’te gösterilen RBFNN, giriş katmanından gizli katmana geçişte 
radyal tabanlı aktivasyon fonksiyonları ve doğrusal olmayan bir kümeleme analizi kullanan çok katmanlı bir yapıya sahiptir [27].

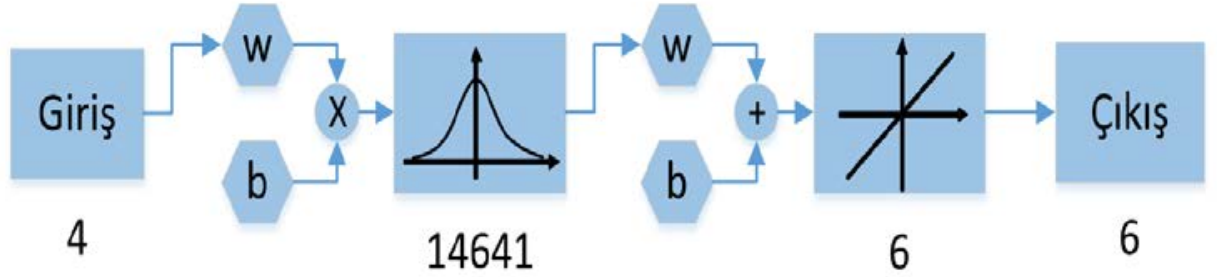

Şekil 5 Radyal tabanlı fonksiyon ağ yapısı

RBFNN ağının boyutu, kullanılan diğer ağlara kıyasla çok daha büyüktür. RBFNN yapısının eğitimi çok boyutlu uzayda eğri uydurma yaklaşımıdır ve kullanılan formüller Denklem 7-10'da verilmiştir [23]

$$
\begin{gathered}
X_{j}=\varphi\left(\left\|\Delta \vec{f}-\overrightarrow{c_{j}}\right\| \times b^{i h}\right) \\
\varphi(x)=\exp \left(-x^{2}\right) \\
b^{i h}=\frac{0.833}{s} \\
C_{i}=b_{i}^{h o}+\sum_{j=1}^{h} w_{j i}^{h o} \times X_{j}
\end{gathered}
$$

burada $\Delta \vec{f}$ giriş vektörünü, $\overrightarrow{c_{J}} \mathrm{j}$. gizli düğümün merkez vektörünü, $b^{\text {ih }}$ radyal tabanlı katmanın eşik terimini, $\varphi$ doğrusal olmayan radyal tabanlı fonksiyonu (Gauss), $b_{i}^{\text {ho }}$ çıkış katmanının eşik değerini, $C_{i}$ i. çıkışı, $w_{j i}^{\text {ho }}$ i. çıkış dügümü ile $\mathrm{j}$. gizli düğüm arasındaki ağırlığı ve $s$ yayılma faktörünü ifade etmektedir.

\section{Tartışma ve Sonuçlar}

Bu çalışmada, rüzgâr türbinlerinde kullanılabilen 14-kutuplu 2,5 kW anma gücünde yüzey yerleştirmeli, içten rotorlu, sabit mıknatıslı senkron generatörün performansının üç farklı yapay sinir ağı modeli kullanılarak kestirimi gerçekleştirilmiştir. Bu amaçla radyal tabanlı fonksiyon sinir ağı, çok katmanlı sinir ağı ve elman sinir ağı modelleri kullanılmıştır.

Yapay sinir ağlarının giriş değişkenleri; kutup yayı/kutup adımı oranı, mıknatıs kalınlığı, kutup yay ofseti ve kaykı olmak üzere dört parametreden oluşmaktadır. Generatörün verimi, çıkış gücü, toplam güç kaybı, vuruntu torku, toplam harmonik bozulma miktarı ve toplam mıknatıs ağırlığı ise yapay sinir ağlarının altı çıkışını belirtmektedir.

Şekil 6-9'da, çıkış parametrelerinin yapay sinir ağı yöntemleriyle kesitirilen ve SEA ile hesaplanan değerlerinin dağılımı verilmiştir. Şekillerden görüldügü üzere vuruntu torku parametresinin kestiriminde diğer parametrelere göre başarı daha düşük olmuştur. Elman ağı ile kestirim yapılırken verim parametresinin kestiriminde en iyi performans elde edilmiştir. 
Çetin et. al
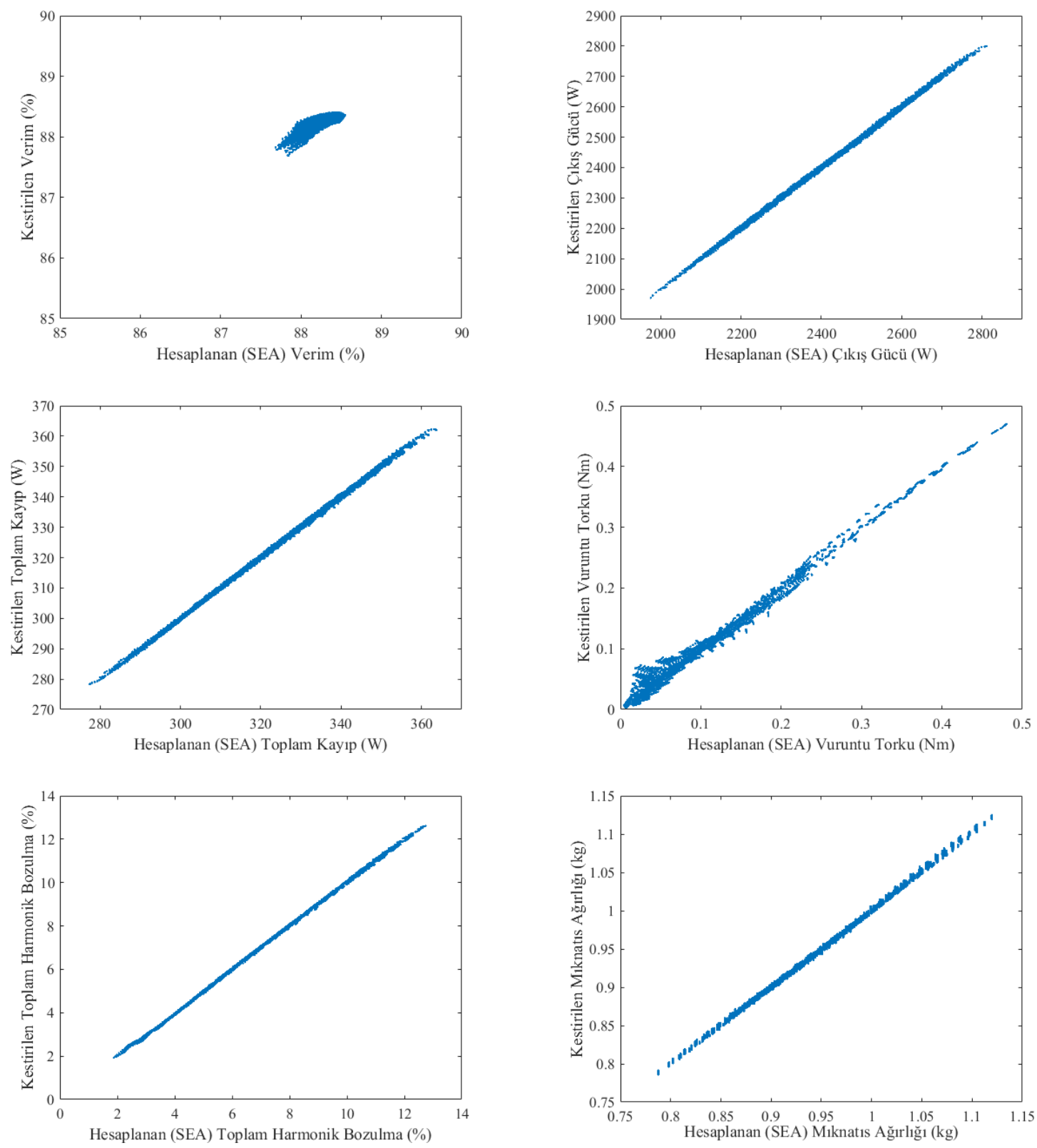

Şekil 6 Elman ağı ile elde edilen parametre kestirim sonuçları

Şekil 6 incelendiğinde, vuruntu torku parametre kestiriminde sağlanan başarı diğer parametrelere nazaran daha düşüktür. Elman ağı için en başarılı kestirim verimde gözlenmesine rağmen diğer şekiller incelendiğinde Elman ağının verim kestiriminde en düşük performansı sergilediği ve diğer ağ modellerinin gerisinde kaldığı görülmektedir. 
Çetin et. al
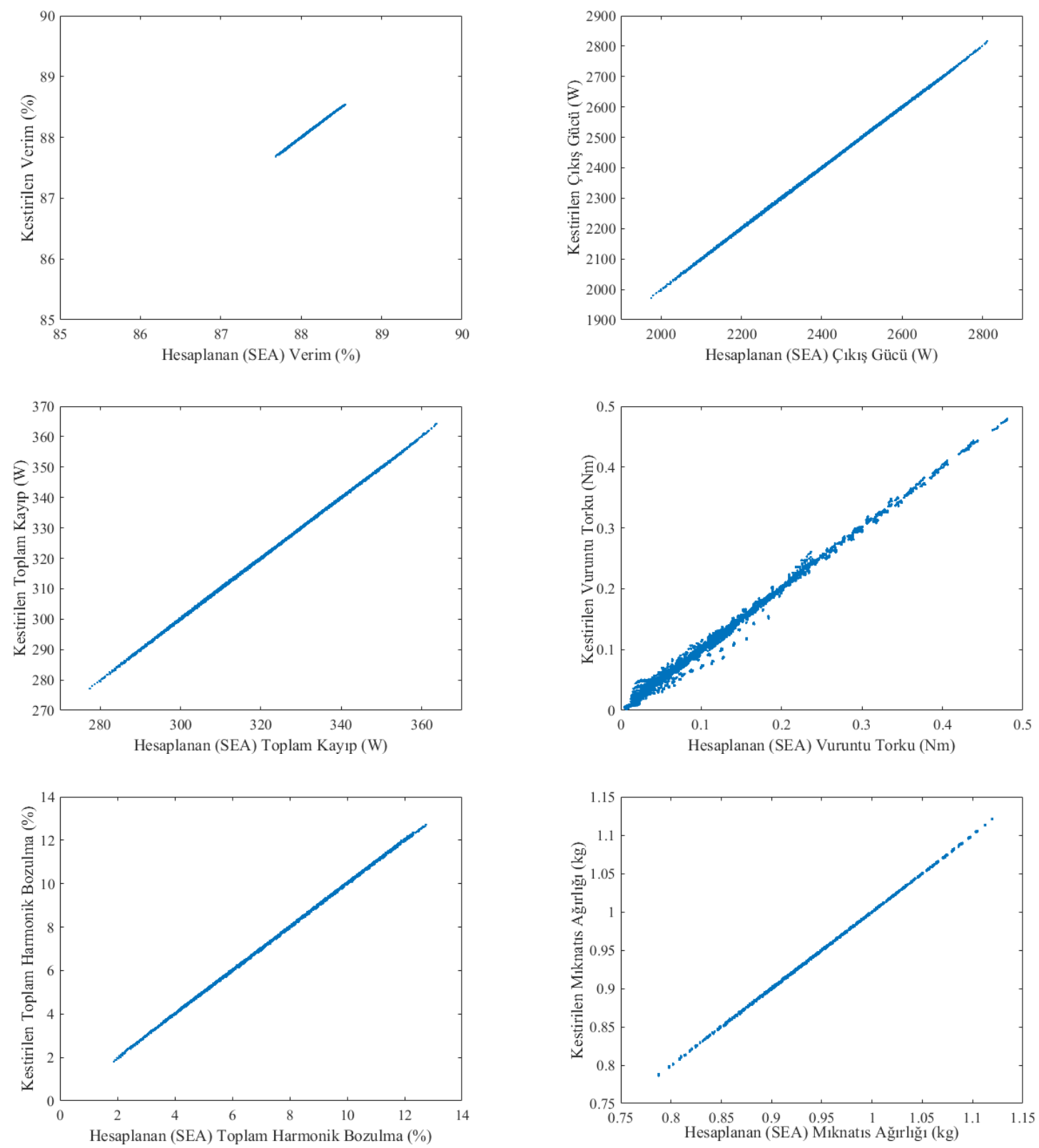

Şekil 7 MLNN (tek gizli katmanlı) ile elde edilen parametre kestirim sonuçları

Şekil 7'de tek gizli katmanlı MLNN için verilen kestirim performansları incelendiğinde, ağ yapısı tıpk1 Elman ağı gibi en başarılı tahimini verim kestiriminde gerçekleştirmiştir. Ayrıca toplam harmonik bozulma miktarının tahmininde de başarılı performans sergilemiştir. Şekilden görüleceği üzere vuruntu torku parametresi için hesaplanan hata değeri diğerlerine nazaran daha yüksektir. 
Çetin et. al
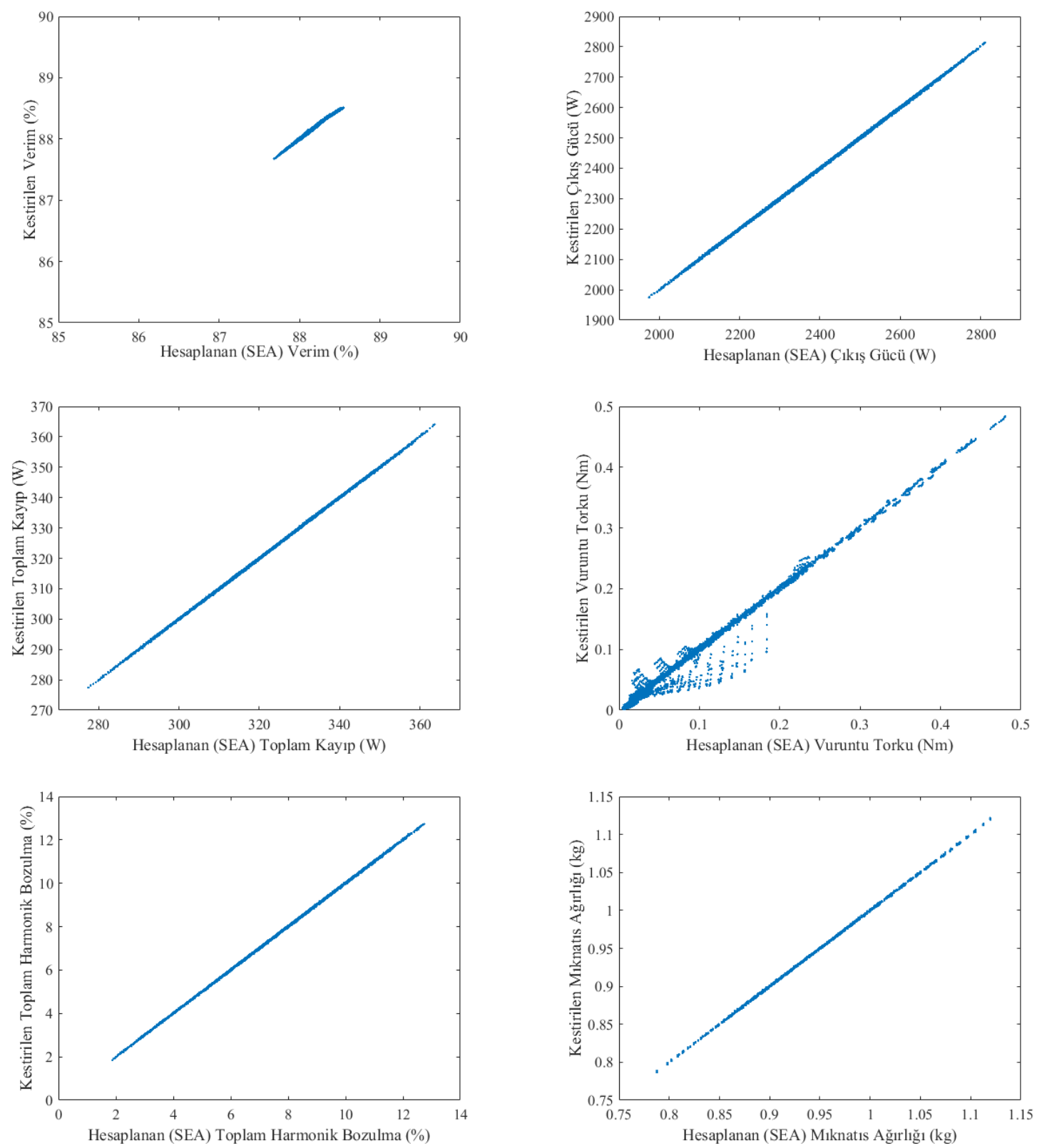

Şekil 8 MLNN (iki gizli katmanlı) ile elde edilen parametre kestirim sonuçları

Şekil 8 ile verilen iki gizli katmanlı MLNN kestirim sonuçları incelendiğinde, ağın özelikle vuruntu torku için en başarılı tahimini gerçekleştirdiği görülmektedir. Her ne kadar vuruntu torku kestiriminde en başarılı ağ yapısı olsa da ağın genel başarısı diğer parametrelerin kestiriminde de göstermiş olduğu performanstan kaynaklanmaktadır. Diğer parametrelerin hesaplanan ve kestirim yapılan değerleri incelendiğinde ağın yüksek başarısı görülmektedir.

RBFNN ile elde edilen parametre kestirim sonuçları incelendiğinde özellikle vuruntu torkunda ağın kestirim performansının düşük olduğu görülmektedir. Buna karşın Şekil 9'dan da görüldüğü üzere RBFNN verim, çıkış gücü, toplam kayıp ve toplam mıknatıs ağırlı̆̆ı parametrelerinin kestiriminde yüksek başarı sergilemiştir. 
Çetin et. al
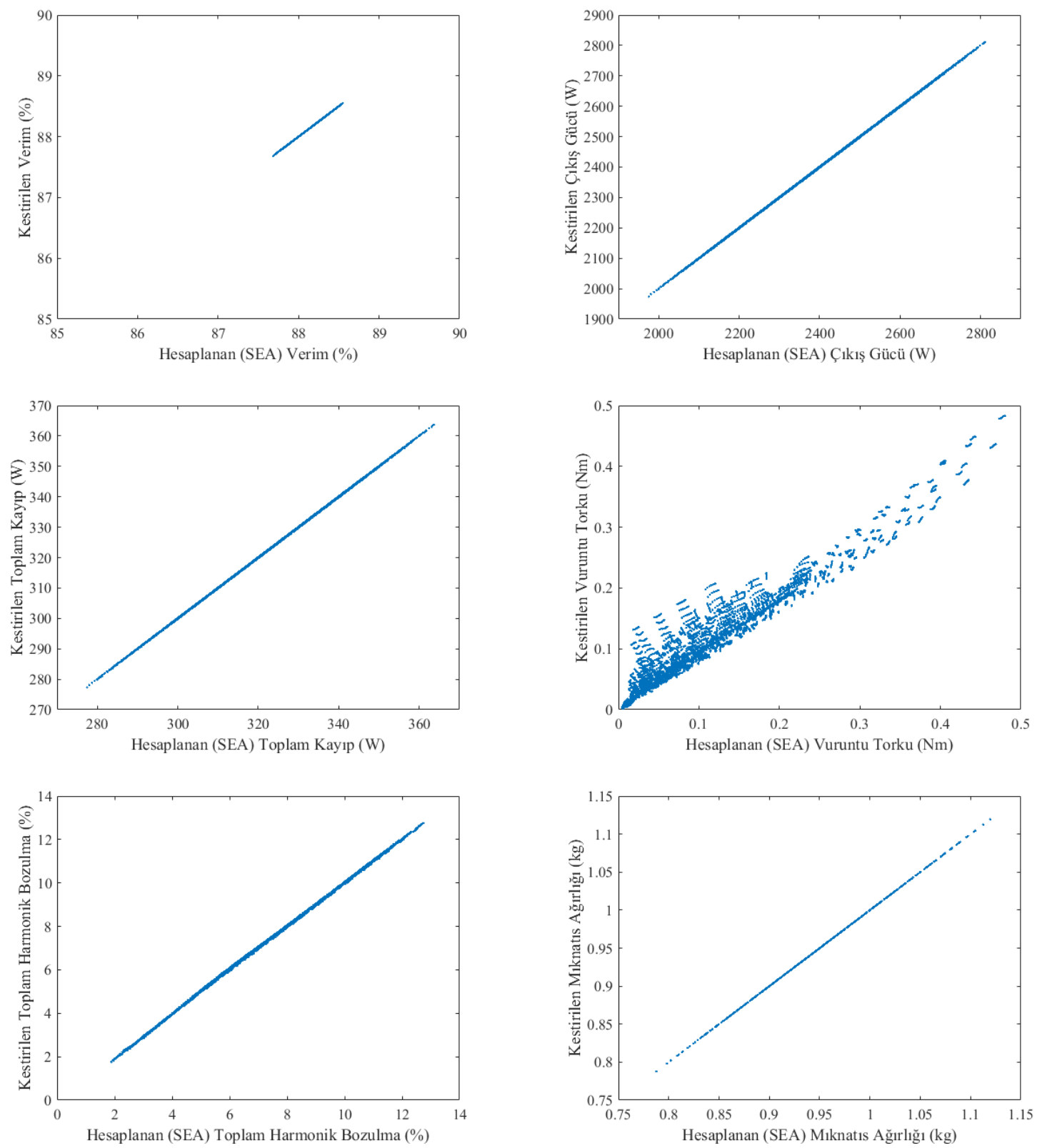

Şekil 9 RBFNN ile elde edilen parametre kestirim sonuçları

Altı çıkış parametresi için farklı sinir ağları ile elde edilen \% hatalar ve ortalama bağıl hata değerleri Tablo 4'te gösterilmiştir. Ortalama bağıl hatalar göz önünde bulundurulduğunda en iyi performansı \%1,4604 hata değeri ile MLNN (iki gizli katmanlı) göstermiştir. Bu modeli sırasıyla \%1,9368 ile MLNN (tek gizli katmanlı), \%2,3346 ile ENN ve \%4,0709 ile RBFNN izlemiştir.

Tablo 4 Performans değerleri

\begin{tabular}{|c|c|c|c|c|c|c|c|}
\hline \multirow[b]{2}{*}{ Yöntem } & \multicolumn{6}{|c|}{ Hatalar (\%) } & \multirow{2}{*}{$\begin{array}{c}\text { Ortalama } \\
\text { Bağıl } \\
\text { Hata (\%) }\end{array}$} \\
\hline & Verim & $\begin{array}{l}\text { Çıkış } \\
\text { gücü }\end{array}$ & $\begin{array}{c}\text { Toplam } \\
\text { kayıp }\end{array}$ & $\begin{array}{l}\text { Vuruntu } \\
\text { torku }\end{array}$ & THD & $\begin{array}{c}\text { Toplam } \\
\text { mıknatıs } \\
\text { ağırlığ }\end{array}$ & \\
\hline ENN & 0,0935 & 0,1553 & 0,1106 & 12,8271 & 0,6415 & 0,1793 & 2,3346 \\
\hline $\begin{array}{l}\text { MLNN (tek gizli } \\
\text { katmanlı) }\end{array}$ & 0,0035 & 0,0633 & 0,0485 & 11,0847 & 0,3671 & 0,0534 & 1,9368 \\
\hline $\begin{array}{l}\text { MLNN (iki gizli } \\
\text { katmanlı) }\end{array}$ & 0,0265 & 0,1172 & 0,0900 & 7,9651 & 0,4356 & 0,1284 & 1,4604 \\
\hline RBFNN & 0,0014 & 0,0431 & 0,0311 & 23,7862 & 0,5636 & 0,0001 & 4,0709 \\
\hline
\end{tabular}


Her bir parametre ayrı ayrı değerlendirildiğinde; verim, çıkış gücü, toplam kayıp ve toplam mıknatıs ağırlığı için en başarılı ağ yapısının RBFNN, vuruntu torku için iki gizli katmanlı MLNN ve \%THD için tek gizli katmanlı MLNN ağı olduğu görülmektedir.

MLNN modelinin ENN yapısına göre performansının daha iyi olması, büyük veriler için LM öğrenme algoritmasının ENN modelinde işletilememesi ve ENN modelinde kullanılan SCG algoritmasının LM algoritması kadar başarılı yakınsama yapamamasından kaynaklanmaktadır.

RBFNN modeli ise diğer ağ yapılarına göre büyük boyutlu olmasına rağmen daha düşük performans göstermiştir. RBFNN'nin yetenekleri büyük ölçüde radyal tabanlı katman düğümlerinin sayısının, konumlarının ve genişliklerinin uygun olup olmadığına bağlıdır. RBFNN'nin boyutu, artan eğitim düzenleriyle artmaktadır. RBFNN, büyük boyutlu problemler için gizli katmanlarda sigmoid nöronları olan MLNN'den çok daha fazla nörona sahip olma eğilimindedir ve bu problemler ile başa çıkmak için pratik değildir [27].

Genel olarak değerlendirildiğinde, kullanılan her bir yöntemin SMSG'nin belirlenen parametrelerini kestiriminde başarılı olduğu söylenebilir. RBFNN, sistem modellemede başarılı sonuçlar vermekle beraber gizli katman nöron sayısı örnek büyüklüğü ile artmaktadır. ENN'nin yapısında bulunan geri besleme bağlantıları, MLNN'ye göre işlem yükünü arttırmaktadır. Bununla birlikte önerilen yöntemler içerisinde en başarılı yöntem \%1,46 ortalama bağıl hata ile iki gizli katmana sahip olan MLNN yapısıdır.

\section{Referanslar}

[1] V. Khare, S. Nema, and P. Baredar, "Solar-wind hybrid renewable energy system: A review", Renewable and Sustainable Energy Reviews, vol. 58, pp. 23-33, 2016.

[2] E. Delihasanlar, E. K. Yaylacı and A. Dalcal, "Solar Energy potential in the world and Turkey, current status, incentives, installation cost analysis-Karabuk province sample”, Electronic Letters on Science \& Engineering, vol. 15, no. 1, pp. 12-20, 2019.

[3] “Elektrik üretim iletim istatistikleri raporu”, [Online]. https://www.teias.gov.tr/tr-TR/turkiyeelektrik-uretim-iletim-istatistikleri. [Erişim: 10.04.2020.]

[4] “Gerçek zamanlı üretim", [Online]. https://seffaflik.epias.com.tr/transparency/uretim/gerceklesen-uretim/gercek-zamanliuretim.xhtml. [Erişim: 10.04.2020.]

[5] H. Polinder, F.F.A. van der Pijl, G.J. de Vilder and P. Tavner, "Comparison of direct-drive and geared generator concepts for wind turbines”, Proc. International Conference on Electric Machines and Drives, 2005, pp. 543-550.

[6] O, Lyan, V. Jankunas, E. Guseinoviene, A. Pasilis, A. Senulis, A. Knolis and E Kurt, "Exploration of a permanent magnet synchronous generator with compensated reactance windings in parallel rod configuration”, Journal of Electronic Materials, pp. 1-7, 2018.

[7] A. Dalcalı, E. Kurt, E. Çelik and N. Öztürk, "Cogging Torque Minimization Using Skewed and Separated Magnet Geometries”, Journal of Polytechnic, vol. 23, no. 1, pp. 223-230, 2020.

[8] A. Dalcal1, M. Akbaba, "Optimum pole arc offset in permanent magnet synchronous generators for obtaining lowest voltage harmonics”, Scientia Iranica D, vol. 24, no. 6, pp. 3223-3230, 2017. 
[9] K.M. Vishnu Murthy, Computer-Aided Design of Electrical Machines. BS Publications, Hyderabad, 2008.

[10] G. Lee, S. Min and J.P. Hong, "Optimal Shape design of rotor slot in squirrel-cage induction motor considering torque characteristics”, IEEE Transactions on Magnetics, vol.49, no.5, pp. 2197-2200, 2013.

[11] A. Dalcal1, M. Akbaba, "Comparison of 2D and 3D magnetic field analysis of single-phase shaded pole induction motors", Engineering Science and Technology, an International Journal, vol.19, no. 1, pp. 1-7, 2016.

[12] S.L. Ho and W.N. Fu, "Review and future application of finite element methods in induction motors,” Electric Machines \& Power Systems, vol. 26, no. 2, pp. 111-125, 1998.

[13] M. Akbaba and S. Q. Fakhro, "An improved computational technique of the inductance parameters of the reluctance augmented shaded-pole motors using finite element method," IEEE Transactions on Energy Conversion, vol. 7, no. 2, pp. 308-314, 1992.

[14] A. Dineva, A. Mosavi, S. F. Ardabili, I. Vajda, S. Shamshirband, T. Rabczuk and K. W. Chau, "Review of soft computing models in design and control of rotating electrical machines", Energies, vol. 12, no. 1049, pp. 1-28, 2019.

[15] A. Dalcal1, O. Çetin, C. Ocak and F. Temurtaş, "Prediction of the force on a projectile in an electromagnetic launcher coil with multilayer neural network", Sakarya University Journal of Computer and Information Sciences, vol. 1, no. 3, pp. 1-10, 2018.

[16] E. Çelik, H. Gör, N. Öztürk and E. Kurt, “Application of artificial neural network to estimate power generation and efficiency of a new axial flux permanent magnet synchronous generator”, Int. J. Hydrogen Energy, vol. 42, pp. 17692-17699, 2017.

[17] M. Ehsani, Y. Gao, and S, Gay, "Characterization of electric motor drives for traction applications”, Proc. 29th Annual Conference of the IEEE Industrial Electronics Society, USA, 2003.

[18] H. W. Jun, J. W. Lee, G.H. Yoon and J. Lee, J. “Optimal design of the PMSM retaining plate with 3-D barrier structure and eddy-current loss-reduction effect, IEEE Transaction on Industrial Electronics, vol. 65, no. 2, pp. 1808-1818, 2018.

[19] B.O. Zala and V. Pugachov, "Methods to reduce cogging torque of permanent magnet synchronous generator used in wind power plants", Elektronika Ir Elektrotechnika, vol. 23, no.1, pp. 43-48, 2017.

[20] Y. Duan, "Method for design and optimization of surface mount permanent magnet machines and induction machines” Ph. D. Thesis, Georgia Institute of Technology, pp. 8-24, 2010.

[21] C. Ocak, "Doğrudan tahrikli asansör sistemlerinde kullanılan sabit mıknatıslı senkron motorlarda mıknatıs geometrisinin motor performansı ve maliyeti üzerindeki etkilerinin incelenmesi”, Mühendislik Bilimleri ve Tasarım Dergisi, vol. 7, no. 4, pp. 825-834, 2019. 
Çetin et. al

[22] F. Temurtas, R. Gunturkun, N. Yumusak, and H. Temurtas, "Harmonic detection using feed forward and recurrent neural networks for active filters," Electr. Power Syst. Res., vol. 72, no. 1, pp. 33-40, 2004.

[23] O. Çetin and F. Temurtaş, "Classification of magnetoencephalography signals by multilayer and radial based artificial neural networks,” Elec Lett Sci Eng, pp. 32-38, 2018.

[24] M. F. Moller, “A scaled conjugate gradient algorithm for fast supervised learning," Neural Networks, vol. 6, pp. 525-533, 1993.

[25] A. Gulbag and F. Temurtas, "A study on quantitative classification of binary gas mixture using neural networks and adaptive neuro-fuzzy inference systems," Sensors Actuators, B Chem., vol. 115, no. 1, pp. 252-262, 2006.

[26] A. Gulbag and F. Temurtas, "A study on transient and steady state sensor data for identification of individual gas concentrations in their gas mixtures," Sensors and Actuators B, vol. 121, no. 1, pp. 590-599, 2007.

[27] A. Gulbag, F. Temurtas, C. Tasaltin, and Z. Z. Öztürk, “A study on radial basis function neural network size reduction for quantitative identification of individual gas concentrations in their gas mixtures,” Sensors Actuators, B Chem., vol. 124, no. 2, pp. 383-392, 2007. 